\title{
THE POSSIBILITIES OF USING INVESTMENT TOOLS BASED ON CRYPTOCURRENCY IN THE DEVELOPMENT OF THE NATIONAL ECONOMY
}

\author{
Olena Bondarenko', Oksana Kichuk ${ }^{2}$, Andrii Antonov ${ }^{3}$
}

\begin{abstract}
The international experience of various countries of the world in the implementation, usage, and economic and legal status of cryptocurrency is compared in this research. The advantages and disadvantages of using cryptocurrency at the present stage of economic and scientific-technical development of Ukraine are considered. The results of the research of the awareness of market participants regarding the advantages and disadvantages of cryptocurrency and the presence of interest in the usage of cryptocurrency are given. The aim of this article is to study the possibilities of using cryptocurrency for economic development. The object of the research is the process of using cryptocurrency in the market in Ukraine, taking into account world experience. Practical implications. The results of a study of the demand for cryptocurrency in Ukraine. The research was conducted with the help of a questionnaire, as a result of which it was found out: the level of awareness of cryptocurrency; subjective perception of cryptocurrency; sources of awareness of cryptocurrency; the presence of the potential interest of Ukrainians in the acquisition of cryptocurrency. It was found what exactly Ukrainians consider the main advantages and disadvantages of cryptocurrency. Value/originality. Cryptocurrency as a means of payment and a type of electronic money is found in the most countries of the world in the "grey" zone, and regulators, if not prohibit, then at least do not recommend citizens to invest in such assets. However, the state of science and technology development of blockchain technologies, which are the basis of cryptocurrency, and the state of demand for cryptocurrency in the Ukrainian market are ready to use cryptocurrency. For the effective implementation of cryptocurrency, Ukraine lacks only the normative framework. Developing a regulatory framework in this area will help to bring cryptocurrency markets to stability. The introduction of international experience in the usage of cryptocurrency in Ukraine, the creation of own model of behaviour will be the first step towards building a transparent and understandable cryptocurrency market, which will lead to the development of the economy as a whole.
\end{abstract}

Key words: cryptocurrency, Bitcoin, demand for cryptocurrency, digital money.

JEL Classification: E40, E42

\section{Introduction}

The digital space of today is constantly changing, every second it becomes more complicated and has no boundaries. Digital technologies are the main trend of the present. Interest is growing, both in the digital technologies themselves and in their products. One of these digital goods is digital money (electronic money/ digital currency). Currently, electronic money has become particularly popular, despite the fact that they appeared relatively recently. This is facilitated by such factors as the convenience of paying for goods in online stores, high speed of transactions, and the use of modern technologies to ensure the security of transactions. One of the most promising types of electronic money is cryptocurrency.

Cryptocurrency is a type of digital money, protected from counterfeiting, which can be stored in electronic wallets, and also transferred from one purse to another. The difference between cryptocurrency and electronic money is that in order to conduct operations with electronic money, money must first be deposited into an account using a payment terminal or a bank. Electronic money is simply a form of presenting the money we use in everyday life. Cryptocurrency is created and produced via the Internet, while it is not associated with any of the usual currencies and is not ensured by something, but

\footnotetext{
Corresponding author:

${ }^{1}$ O.S. Popov Odesa National Academy of Telecommunication, Ukraine.

E-mail: BondarenkoO@ukr.net

${ }^{2}$ Odessa National Economic University, Ukraine.

E-mail: ok_5@ukr.net

${ }^{3}$ Zhytomyr State Technological University, Ukraine.

E-mail: d-38-053-03@ukr.net
} 
it has its own market and supporters. Discussions that are being conducted about cryptocurrency, both in the Central Banks and the governments of many countries and in the business environment, unanimously require a scientific and economic approach.

So, the problems of implementation, research, possibilities of usage, regulation, circulation, and control of cryptocurrency are relevant issues for all countries of the world at present. Many domestic and foreign authors (Amarnath, 2018; Higbee, 2018; Ibrahim, 2018; Swammy et al., 2018; Thapar, Chandel, 2018; Orme, 2019) were engaged in the study of this problem, but still didn't find a common solution, which led to the choice of the theme of this research.

The aim of this article is to study the possibilities of using cryptocurrency for economic development.

\section{The concept of cryptocurrency}

In the modern world, computerization and internetization of almost all spheres of human life are proceeding at an enormous pace. These processes could not but affect the financial system of society. In recent years, both banks and other financial institutions have penetrated the worldwide network, smartphones, and computers. But it was a process of adapting the existing functions of the system to the modern consumer of financial services, taking into account developing technologies. Instant payments, online account access, and the ability to instant contactless payment for goods have changed the financial relations vision (Swammy, 2018).

In 2008, a unique inherently experiment began. Satoshi Nakamoto presented to the world an alternative financial system and Bitcoin cryptocurrency. After three years of development by enthusiasts and cyber anarchists, in 2012 the system began to gain popularity and they started talking about cryptocurrency at the level of states and international organizations (Shipra, 2017).

Bitcoin e-currency was launched in 2009. This is the first fully decentralized electronic monetary unit in the world, in which there is no single emission centre at all, operations within which are built on peer-to-peer information exchange technologies. Cryptocurrency is the so-called currency of a new generation, the software for which is distributed on the principles of open access, all payments in which are completely anonymous and are not controlled by anyone and cannot be controlled technically, even with a strong desire, and the work of cryptocurrency can be neither stopped nor blocked. For any transaction within the system (in both directions) $0 \%$ is taken, in this respect, it is a unique, completely free payment system (Sreedharan, 2019).

The question "Is cryptocurrency money?" is still open in most countries of the world. It exists only in the virtual space, which means that it does not have a physical counterpart. The cryptocurrency is based on computer code, that is, it itself is only encrypted data that cannot be copied, which means that such a unit of currency is relatively protected from falsification.

At the moment, there are more than 2000 different types of virtual money. The popularization of virtual money is growing every year, as it is shown in Table 1.

Table 1

The release of cryptocurrency in 2009-2017

\begin{tabular}{|l|c|l|}
\hline Cryptocurrency & $\begin{array}{c}\text { Start of } \\
\text { Exploitation }\end{array}$ & \multicolumn{1}{|c|}{ Upper Bottom Line } \\
\hline Bitcoin & 2009 year & 21 million \\
\hline Litecoin & 2011 year & 84 million \\
\hline Peercoin & 2012 year & upper bottom line is absent \\
\hline NXT & 2013 year & 1 billion \\
\hline 42 coin & 2014 year & 21 million \\
\hline Ethereum & 2015 year & upper bottom line is absent \\
\hline Zcash & 2016 year & 21 million \\
\hline Deeponion & 2017 year & 25 million \\
\hline
\end{tabular}

At the moment, the most popular are Bitcoin, Ethereum, and Ripple (Table 2). Essentially, these are all different types of cryptocurrency. Bitcoin is based on blockchain technology. Ripple has its own system. Ethereum is a multifunctional platform based on blockchain technology. As of November 29, 2018, the market capitalization of cryptocurrency in the world amounted to $\$ 9,184,235,808,826$, while $75 \%$ of this amount falls on the top 10 leaders in the rating of digital currencies. According to the World Economic Forum in Davos, Ukraine entered the top 14 of the leading countries of the blockchain (manufacturing techniques and cryptocurrency transactions).

Table 2

Top-5 leaders of the rating of cryptocurrency in 2018

\begin{tabular}{|c|l|c|c|c|}
\hline$№$ & Currency & Price & Capitalization & Changes (24h.) \\
\hline 1 & Bitcoin & $4250,1 \$$ & $73946584628 \$$ & $+5.9756 \%$ \\
\hline 2 & Ripple & $0.3865 \$$ & $38646850331 \$$ & $+3.3146 \%$ \\
\hline 3 & Ethereum & $121.36 \$$ & $12559784724 \$$ & $+6.2325 \%$ \\
\hline 4 & $\begin{array}{l}\text { Bitcoin } \\
\text { Cash / BCC }\end{array}$ & $211.74 \$$ & $3684013134 \$$ & $+3.2475 \%$ \\
\hline 5 & EOS & $3.16 \$$ & $3231818774 \$$ & $+0.9585 \%$ \\
\hline
\end{tabular}

The development of cryptocurrency has led to the fact that it has become a profitable object for investing funds. So, new methods and ways of investing appear on the market, which causes the interest of many investors and is connected with the lifecycle of cryptocurrency as an investment (Koval et al., 2018).

Themain ways toinvestin cryptocurrency:a) speculation on the course - the purchase of a cryptocurrency and its further sale; b) mining - the use of powerful computing, "farm", in solving complex mathematical problems to create cryptocurrency; c) cloud mining - the purchase of computing power for rent; d) ICO - release of a cryptocurrency, during which you can raise funds for the development of an investment project. 
The most profitable but at the same time risky way of investing is ICO, relatively safe and less profitable - Mining. In comparison, the available method is speculation on the course. But, to identify the prospects and risks of using cryptocurrency as an investment tool, it is necessary to consider the main advantages and disadvantages of a cryptocurrency.

\section{Advantages and disadvantages of cryptocurrency}

The cryptocurrency inventors assert that the usage of their product is reliable and effective, as evidenced by the presence of a number of advantages, which are given in Table 3, but there are also disadvantages (Amarnath, 2018).

Some features inherent in cryptocurrency are considered ambiguous. These include decentralization and anonymity. The problem of decentralization lies in the lack of control and tracking of the release and movement of virtual money by users or government bodies since these operations are a programmed process embedded in the algorithm (Parashar, 2018). Anonymity is another controversial issue, which, on the one hand, increases the attractiveness of the use of cryptocurrency by ordinary people since it is not taxed by the state, and on the other, it provides wide opportunities for the implementation of criminal activity (Thapar, 2018). The analysis of disadvantages and ambiguous moments makes it clear that the reverse side of the coin outweighs the benefits of this currency unit because it not only provides an opportunity to simplify the conduct of financial transactions but also provokes the growth of Internet fraud (Sigler, 2018).

Recently, we have witnessed a sharp increase in the number of attacks on cryptocurrency using the capabilities of victims' computers for cryptocurrency mining. And alternative currencies also play an important role in extortion attacks, being the best way of payment (Higbee, 2018). However, the demand for cryptocurrency necessitates the development of methods for combating cybercrime in general and crypto fraudsters in particular. Thus, researchers from the University of Cambridge (Orme, 2019) are investigating methods for combating cybercrime on the basis of biometric technologies.

However, there are also significant advantages to which, moreover, is added the possibility of using cryptocurrency as an investment instrument (Ibrahim, 2018).

\section{World experience of using cryptocurrency}

On October 22, 2015, the European Court ruled that Bitcoin should be considered a currency, not a commodity, at least in terms of taxation. It should be noted that the decision of the European Court allows for a divergence of opinion in the EU states on the essence and regulation of the cryptocurrency. Each country can have its own opinion on what Bitcoin is - a currency or a commodity.

In February 2018, the German Finance Ministry signed a decree according to which Bitcoin is a means of payment. Cryptocurrency purchases will be subject to value-added tax. However, the sale of Bitcoin will not be subject to capital gains tax. Germany now officially defines Bitcoin as a currency - as stated in the decree of the Ministry of Finance, cryptocurrency becomes the equivalent of legal means of payment, as they are used by transaction participants as an alternative contractual and immediate method of payment. The manual, published by the agency on $02 / 27 / 2018$, distinguishes Germany from the United States, where Bitcoin is considered the property for tax purposes. That is, if an American buys something with the help of Bitcoin, then technically it is considered as a sale of property and is subjected to capital gains tax.

In percentage terms, Turkey ranks first in the world in the number of private owners of digital currencies. According to statistics, $18 \%$ of the population (more than 14 million people) have certain virtual assets. The government plans to create a national cryptocurrency.

Saudi Arabia has banned the trade of cryptocurrency. The government is working on establishing its own cryptocurrency. They also have a positive attitude to the blockchain. The Islamic Development Bank uses financial platforms based on this technology.

Table 3

Advantages and disadvantages of cryptocurrency

\begin{tabular}{|l|l|l|}
\hline \multicolumn{1}{|c|}{ Advantages } & \multicolumn{1}{|c|}{ Disadvantages } & Ambiguous features \\
\hline - availability of money at any time; & - the impossibility of monitoring and tracking & - decentralization; \\
- the cryptocurrency cannot be removed, it does not disappear after & the movement of Internet currency; & - anonymity. \\
a period of time and always remains with the owner until the owner & - the impossibility of withdrawal of payment; \\
uses it; & $\begin{array}{l}\text { - the absence of a single, coordinating trade } \\
\text { organizer; }\end{array}$ & \\
- lack of commission; & - doubtful reliability and security of storage \\
- the emission is realized strictly according to the given algorithm; \\
- cryptocurrency is independent of the influence of the Central Bank \\
and the government; & $\begin{array}{l}\text { and money transfer operations; } \\
\text { - constant rate fluctuations; } \\
\text { - cryptocurrency is not subject to inflation. }\end{array}$ & \\
\hline
\end{tabular}

Source: based on (Higbee, 2018; Ibrahim, 2018; Orme, 2019; Sigler, 2018) 
At the same time, China banned mining and all operations with cryptocurrency and announced the closure of the exchanges. Actually, China quickly found how to circumvent the taboos on the ICO and continued to mine and sell cryptocurrency, but through the Hong Kong markets where this law does not apply.

The most publicity cryptocurrency received in Japan. By March 2014, the Bank of Japan did not have any plans to regulate Bitcoin turnover. However, after the collapse of Mt.Gox, based in Tokyo, the Japanese authorities announced the need to control this market. Starting from March 2016, Bitcoin received legal tender status in Japan.

This was the catalyst for the development of cryptocurrency and the Japanese increased their activity in the Bitcoin market. Everything can be bought for the cryptocurrency, and they gradually refuse from real money. Now with the help of Bitcoin, you can pay in the largest trade networks and supermarkets. Some firms have promised to pay employees a bitcoin salary. The government says that it is important for a transparent economy, and besides, it is a component of reducing the negative impact on the environment due to saving natural resources and reducing waste in the production of banknotes. Indeed, when calculating cryptocurrency, it is much more difficult to carry out fraud.

So, regulators in different countries have not yet found a consensus in determining the legal status of virtual currency (Ulyanava, 2018). In different countries, cryptocurrency is considered as various objects, as it is shown in Table 4.

So, in the majority of states, there is no appropriate regulation, therefore, the legal regime of cryptocurrency is not fully defined, and transactions with it are in the "grey" zone.
In Ukraine, the attitude towards cryptocurrency is ambiguous. On October 6, the draft law of Ukraine No. 7183 "On the Circulation of Cryptocurrency in Ukraine" was provided. But it was not accepted and handed over for revision, motivating this by the fact that today the international community has not defined unique approaches to regulating the circulation of cryptocurrency. Also, according to Article 99 of the Constitution of Ukraine, the hryvnia is the monetary unit of Ukraine. Also in part 1 of Article 192 of the Civil Code of Ukraine, it is established that the legal unit of payment obligatory for acceptance at face value throughout the territory of Ukraine is the currency of Ukraine - the hryvnia. This is also highlighted by Article 3 of the Law of Ukraine "On Payment Systems and Transfer of Funds in Ukraine" (Law of Ukraine 2473-VIII, 2001). At the same time, the draft law states that it is possible to exchange cryptocurrency not only for money but also for securities, services, goods, and so on. This actually equates the program code, which determines the cryptocurrency in the draft law, to money. Indeed, in this case, the software code will be provided with such functions of money as a means of payment, preservation of value and accumulation. So, currently in Ukraine, there is not a single law or a sublegal regulatory act that would regulate cryptocurrency transactions. Now two bills have been registered in the Verkhovna Rada of Ukraine, which are designed to resolve this issue: Draft Law No. 7183 dated October 6, 2017 "On the Circulation of Cryptocurrency in Ukraine" (Law of Ukraine 7183-1, 2017), Draft Law No. $7183-1$ as of $10 / 10 / 2017$ "On Stimulating the Market of Cryptocurrencies and Their Derivatives in Ukraine" (Law of Ukraine 7183, 2017). Both bills

Table 4

Worldwide experience in determining the legal status of cryptocurrency

\begin{tabular}{|c|c|c|}
\hline Country & $\begin{array}{l}\text { Definition of the legal status } \\
\text { of virtual currency }\end{array}$ & Tax regulation \\
\hline USA & Property & $\begin{array}{l}\text { The property, is taxed in accordance with the rules that apply to property taxation and } \\
\text { capital gains tax. }\end{array}$ \\
\hline China & Forbidden & - \\
\hline Japan & Means of payment & Not taxable \\
\hline Bulgaria & Financial asset & Cryptocurrency is exempt from VAT in accordance with what currency it is. \\
\hline France & Financial asset & $\begin{array}{l}\text { Cryptocurrency revenues are classified as industrial and commercial profits } \\
\text { or non-commercial profits, with the result that the capital gains tax is } 19 \% \text { in addition } \\
\text { to the generalized social contribution (CSG) - } 17.2 \% \text {. }\end{array}$ \\
\hline Canada & Property right & The property, is taxed in accordance with the rules that apply to property taxation. \\
\hline Great Britain & Foreign currency & Tax rules for foreign currency transactions. \\
\hline Switzerland & Valuable property & $\begin{array}{l}\text { The fact of possession of cryptocurrency should be reflected in the tax declaration, } \\
\text { and property tax is to be paid from its value. }\end{array}$ \\
\hline Australia & Assets & $\begin{array}{l}\text { The mining and exchange of cryptocurrency for commercial purposes in Australia is } \\
\text { considered exchange trading and is subject to applicable taxes. However, for individuals, } \\
\text { there are cases of exemption from taxation of transactions, if cryptocurrency is used } \\
\text { as a payment for goods or services for personal use only. }\end{array}$ \\
\hline Russia & Highly speculative investment & The system of regulation and taxation of cryptocurrencies is not developed. \\
\hline
\end{tabular}

Source: based on (Duchenko, 2018; Higbee, 2018; Ibrahim, 2018; Orme, 2019) 
determine the need for public administration in the field of cryptocurrency circulation, the authority of the regulator to determine the order of creation and activity of cryptocurrency exchanges, monitor cryptocurrency transactions, and identify subjects of cryptocurrency operations (Duchenko, 2018).

Based on the fact that the National Bank of Ukraine implements monetary policy in the state, one also needs to obtain an expert opinion from the National Bank of Ukraine regarding the project. Therefore, while in Ukraine, Bitcoin and other cryptocurrencies have not been banned, but they have not been recognized with money. At the same time, in Ukraine, many online stores and regular shopping centres accept cryptocurrency. In Kyiv, for the first time in the world, they sold an apartment for the cryptocurrency. According to the interchange agreement, the property was exchanged for the Ethereum cryptocurrency. One can also pay in a cafe using Bitcoin not only in the USA, Germany or Japan but in several dozens of countries - Estonia, Denmark, Sweden, Croatia, Belarus.

\section{Research of demand for cryptocurrency in Ukraine}

Despite the imperfection of the legal framework, the cryptocurrency market is constantly developing and spreading. In order to determine the level of readiness of the Ukrainian market for the introduction of cryptocurrency and the demand for it, on the basis of the Educational and Scientific Institute of Economics and Management of the Odessa National Academy of Telecommunications named after O. S. Popov conducted a study on the knowledge of Ukrainians in cryptocurrency, their attitude to the advantages and disadvantages of cryptocurrency, as well as the desire to join the use of cryptocurrency.

The study was conducted using the questionnaire method. Respondents were asked to fill out questionnaires in Google form, in electronic form.
The survey included 450 respondents aged from 17 to 70 years. Among them:

- from 17 to 25 years - 334 respondents, which amounted to $74.2 \%$;

- from 26 to 45 years old - 107 respondents, which amounted to $23.8 \%$;

- from 46 to 70 years and older - 9 respondents, which amounted to $2 \%$.

To the question "Do you know what cryptocurrency is?" 450 respondents answered that makes up 100\%, $2 \%$ 9 respondents did not answer. Of these, 441 respondents were aware of what cryptocurrency is, accounting for $98 \%$. They did not know what cryptocurrency is 9 respondents (2\%). These respondents did not answer the questionnaire further.

To the next question: "What is cryptocurrency for you?" (Figure 1), 441 respondents answered, that makes up $98 \%$, of which 204 (45.3\%) of respondents consider cryptocurrency primarily as a means of payment (money); 173 (38.4\%) respondents consider cryptocurrency as a means of accumulation. In general, 48 Ukrainians surveyed (10.7\%) perceive cryptocurrency as a means of speculation. Interestingly, only 16 respondents (3.6\%) perceive cryptocurrency as "all of the above", as well, understand its diversity and versatility.

To the question "How did you know about cryptocurrency?” (Figure 2) 441 respondents answered that makes up $98 \%$.

According to the survey, the majority of respondents, namely 186 , which is $41.3 \%$, learned about cryptocurrency in the educational institution where they study. From our point of view, these are positive trends, since it is in educational institutions that complete, comprehensive, and most importantly, high-quality knowledge is obtained (Stankevych, 2015). A rather large percentage of respondents - $89(19.8 \%)$ - derive information about cryptocurrency from the media/ Internet and as much from friends. 77 respondents (17.1\%) learned about cryptocurrency, purposefully pursuing their own self-development and self-education. Unfortunately, not a single respondent indicated that

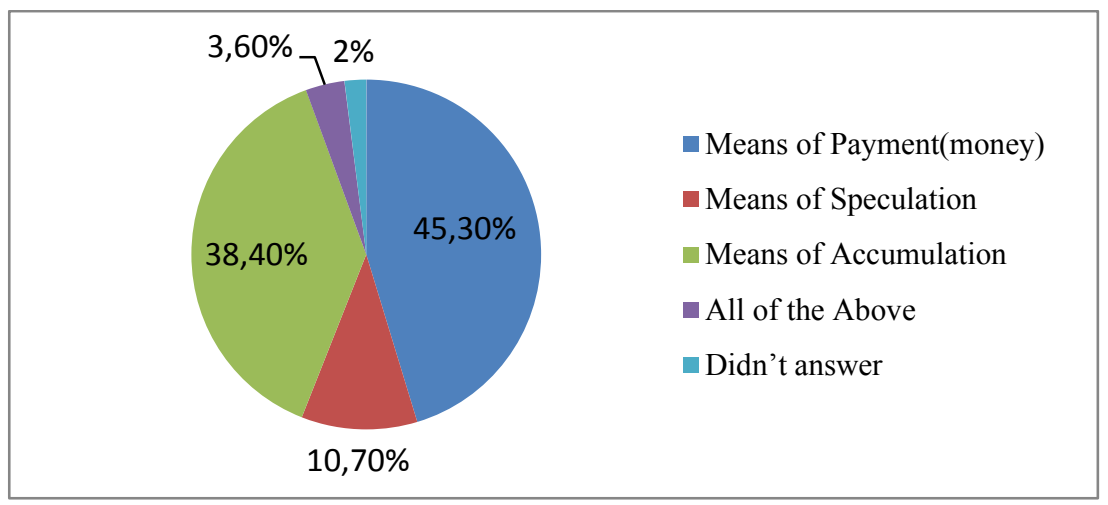

Figure 1. Subjective perception of cryptocurrency by Ukrainians

Source: the author's calculations 


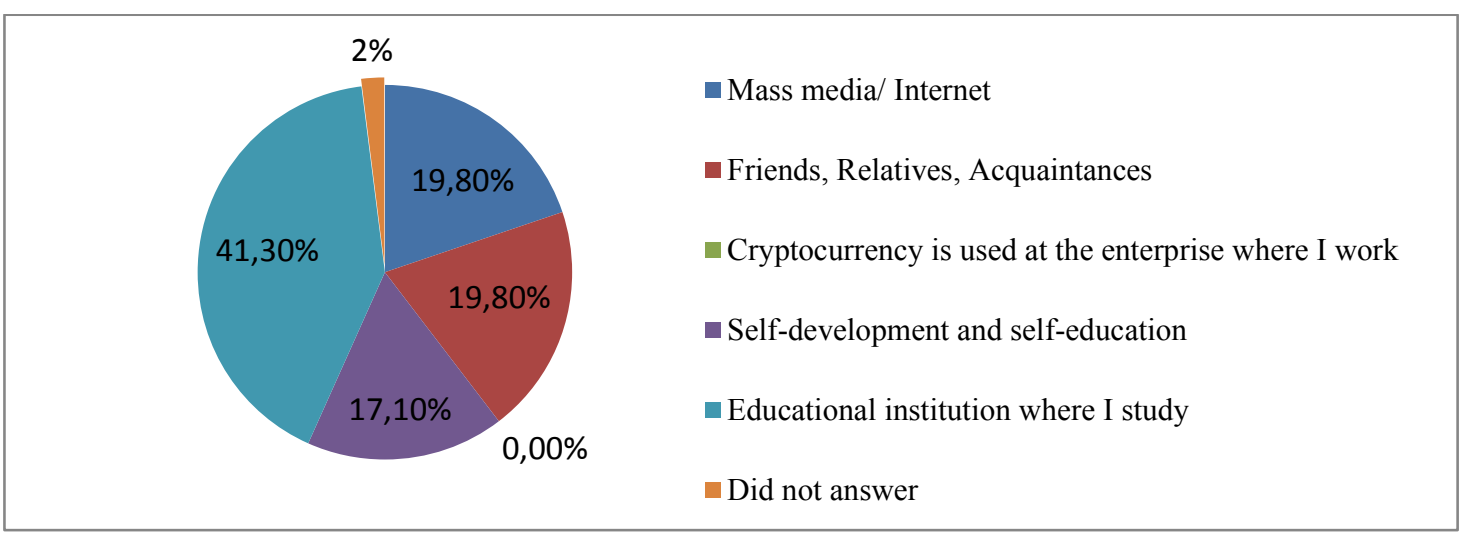

Figure 2. Sources of information on cryptocurrency of Ukrainians

Source: the author's calculations

the source of its awareness about cryptocurrency is the company where the respondent works. However, this is a natural consequence of the lack of a legislative framework governing cryptocurrency issues.

To the question "Do you use (use) you a cryptocurrency?" 441 respondents answered that makes up $98 \%$, of which 45 Ukrainians (10\%) that they have already used or used before cryptocurrency; 76 respondents (16.9\%) are going to use cryptocurrency. This indicates the interest and commitment of potential cryptocurrency consumers. However, a large number, 320 respondents, accounting for $71.1 \%$, did not use, do not use and, so far, do not plan to use cryptocurrency.

To the question "What are the drawbacks of cryptocurrency, in your opinion, that are significant?" (Figure 3) 441 respondents answered that makes up $98 \%$.

Ukrainians consider the possibility of fraudulent schemes to be the biggest disadvantage of cryptocurrency; this is exactly the answer given by 248 respondents, accounting for $55.1 \%$. At the same time, no respondent noticed anonymity as a lack or threat of a cryptocurrency, despite the fact that most fraudulent schemes are possible, precisely because of the anonymity of the cryptocurrency (Orme, 2019; Sigler, 2018; Thapar, Chandel, 2018).

Also, many respondents - 202 Ukrainians (44.9\%) consider the lack of a legislative base for cryptocurrency to be a significant disadvantage. A few respondents, namely 124 (27.6\%), consider cryptocurrency exchange rate fluctuations to be a significant drawback, and 108 respondents (24\%) attribute lack of demand for cryptocurrency to disadvantages.

To the question "Which of the advantages of cryptocurrency, in your opinion, are essential?” (Figure 4) 441 respondents answered - that is $98 \%$.

The most important advantage of cryptocurrency, the majority of polled Ukrainians, 273 people, which is $60.7 \%$, considers its independence from political events in the state. 209 respondents, 46.4\%, believe that the advantage of a cryptocurrency is the ability to use it as a reliable means of payment. 113 respondents, $25 \%$ of respondents, consider cryptocurrency anonymity to be the advantage. 96 respondents $(21.4 \%)$ believe that cryptocurrency has a fairly high level of security. The smallest number of 64 respondents, accounting for $14.3 \%$, considers that the advantage is fluctuations in the cryptocurrency rate.

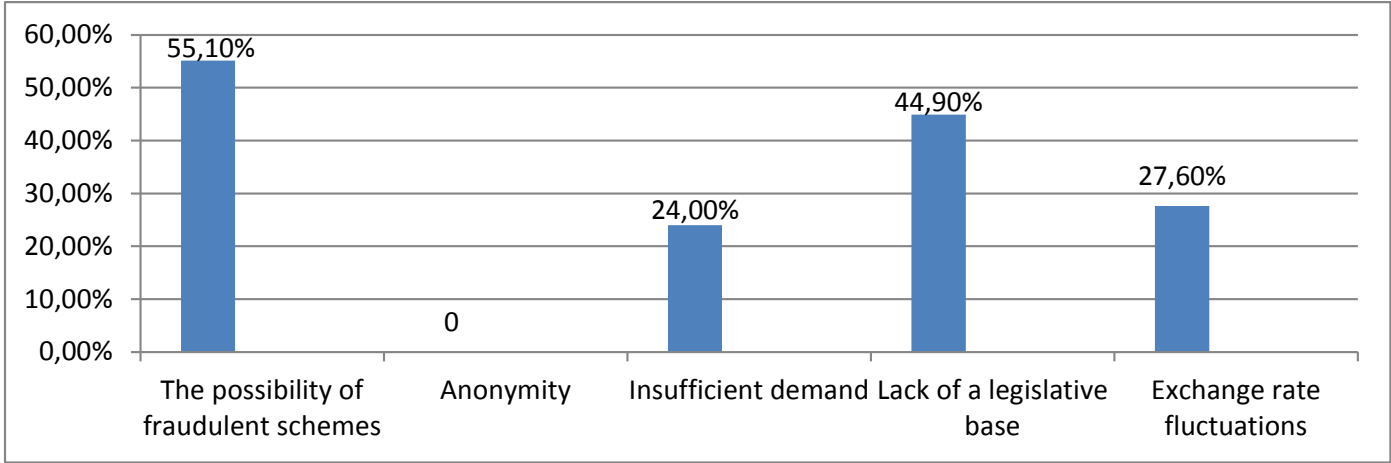

Figure 3. The most important, according to Ukrainians' point of view, disadvantages of the cryptocurrency Source: processed by the authors 


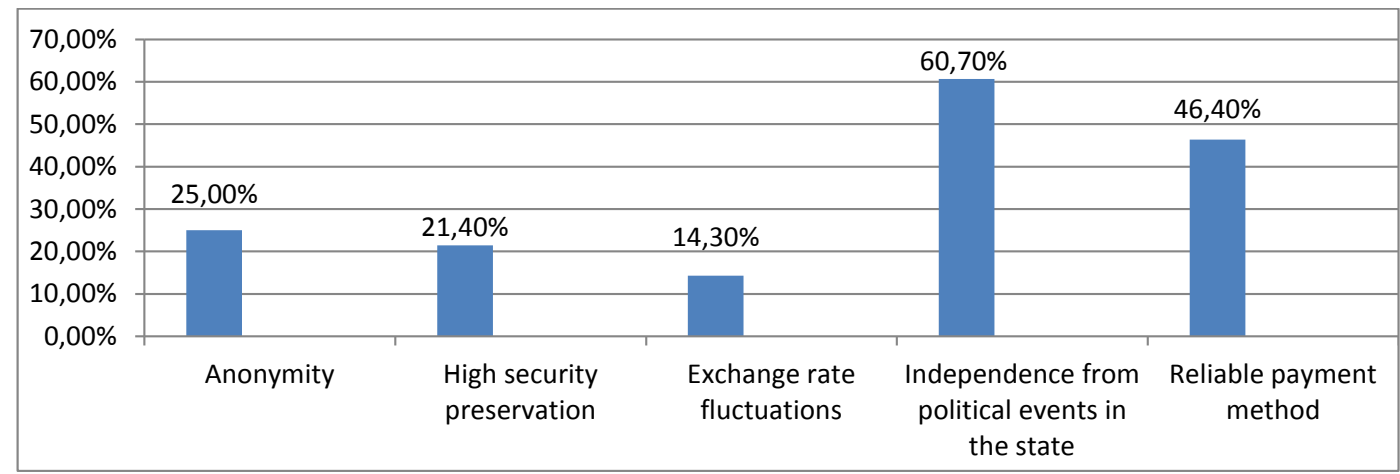

Figure 4. Significant, according to the Ukrainians' point of view advantages of a cryptocurrency

Source: processed by the authors

\section{Conclusions}

The position of the cryptocurrency in the world is ambiguous. Many large countries still recognize it, if not a means of payment, then a kind of electronic money. At the same time, many countries are in no hurry to make conclusions and want to better explore the market of cryptocurrency and the possibility of its regulation. At the same time, cryptocurrency is located in the "grey" zone in the most countries of the world, and regulators, if not prohibit, at least do not recommend citizens to invest in such assets.

The research showed that $21.4 \%$ of the polled Ukrainians consider the cryptocurrency anonymity to be its advantage and no one considers this a disadvantage. At the same time, the majority of respondents, $55.1 \%$, see the main disadvantage of the cryptocurrency - the possibility of fraudulent schemes, without at all associating it with the anonymity of cryptocurrency. Despite this, a large number of respondents $(46.4 \%)$ consider cryptocurrency a reliable means of payment and (21.4\%) savings with a high level of security.

The opinion of the respondents towards the fluctuations of the cryptocurrency rate is unanimous. Thus, rate fluctuations as an advantage are considered by $14.3 \%$ of respondents, and as a disadvantage by $27.6 \%$.

However, the majority of Ukrainians consider themselves aware of cryptocurrency (98\%) and ready for its use (45 Ukrainians, (10\%) have already used or used cryptocurrency, and 76 respondents (16.9\%) are going to use it).

So, the state of scientific and technological development of blockchain technologies, which are the basis of cryptocurrency and the state of demand for cryptocurrency in the Ukrainian market, are ready for the use of cryptocurrency. For the productive implementation of cryptocurrency, Ukraine lacks only the regulatory framework. Despite the different attitudes towards cryptocurrency, the volume of transactions with cryptocurrency and its capitalization is constantly increasing. Therefore, state financial institutions all around the world cannot continue to ignore the existence of this global phenomenon; this is not only economically wasteful but also dangerous for the country's economic system. The timeliness of the project is important for its success, regardless of the readiness of the legislative base to adopt it. The fate of cryptocurrency and blockchain technology should be decided by market needs. Experts believe that the development of a regulatory framework in this area will help bring cryptocurrency markets to stability. The introduction of international experience in using cryptocurrency in Ukraine, creating its own model of behaviour that is the most appropriate for our country will be the first step towards building a transparent and understandable cryptocurrency market that will lead to the development of the economy as a whole.

\section{References:}

Amarnath DG, A. (2018). Crypto Currency: An Illusion. International Journal of Economics and Management Studies, 5(1), 25-34. doi: 10.14445/23939125/ijems-v5ilp105

Duchenko, M. M., Pavlenko, T. V. (2018). The specifics of the formation of the crypto-currency market in Ukraine. Efektyvna ekonomika, (12). doi: 10.32702/2307-2105-2018.12.109

Higbee, A. (2018). The role of crypto-currency in cybercrime. Computer Fraud \& Security, (7), 13-15. doi: $10.1016 /$ s1361-3723(18)30064-2

Ibrahim, M. (2018). Crypto Currency as an Emerging Investment Instrument: The Missing Link. SSRN Electronic Journal. doi: 10.2139/ssrn.3144187

Koval, V., Prymush, Y., Popova, V. (2017). The Influence of the Enterprise Life Cycle on the Efficiency of Investment. Baltic Journal of Economic Studies, 3(5), 183-187. doi: 10.30525/2256-0742/2017-3-5-183-187 
Law of Ukraine 2473-VIII (2001). On payment systems and transfer of funds in Ukraine. Retrieved from: http://zakon.rada.gov.ua/laws/show/2346-14

Law of Ukraine 7183 (2017). About crypto-currency circulation in Ukraine. Retrieved from: http://w1.c1.rada.gov.ua/ pls/zweb2/webproc4_1?pf3511=62684

Law of Ukraine 7183-1 (2017). On stimulation of the market of crypto-currencies and their derivatives in Ukraine. Retrieved from: http://w1.c1.rada.gov.ua/pls/zweb2/webproc4_1?pf3511=62710

Manimuthu, A., Sreedharan, V. R., Marwaha, D. (2019). A literature review on Bitcoin: Transformation of crypto currencyinto a global phenomenon. IEEE Engineering Management Review, 99, 1-1. doi: 10.1109/emr.2019.2901431 Orme, D. (2019). Is biometrics the answer to crypto-currency crime? Biometric Technology Today, (2), 8-10. doi: $10.1016 / \mathrm{s} 0969-4765(19) 30025-6$

Parashar, N., Rasiwala, F. (2018). A study on investor's awareness and perception regarding investment in Crypto currency with special reference to Bitcoin. International Journal of Scientific and Research Publications (IJSRP), 8(12). doi: 10.29322/ijsrp.8.12.2018.p8442

Shipra Saraswat, Vishal Singh Chauhan \& Neetu Faujdar (2017). Analysis on crypto-currency. International Journal of Latest Trends in Engineering and Technology, 9, 185-189. doi: 10.21172/1.91.28

Sigler, K. (2018). Crypto-jacking: how cyber-criminals are exploiting the crypto-currency boom. Computer Fraud \& Security, (9), 12-14. doi: 10.1016/s1361-3723(18)30086-1

Stankevych, I. (2015). Essence of higher education quality concept in modern development conditions. Economic Annals-XXI, 9-10, 60-63.

Swammy, S., Thompson, R., Loh, M. (2018). Crypto Currency: The Birth of an ICO. Crypto Uncovered, 85-131. doi: 10.1007/978-3-030-00135-3_6

Thapar, G., Chandel, P. (2018). Bitcoin: The Crypto Currency and the Dark Web. International Journal of Computer Science and Engineering, 5(8), 6-7. doi: 10.14445/23488387/ijcse-v5i8p102

Ulyanava, K. (2018). Legal Regulation of the Crypto-Currency Taxation. Open Journal for Legal Studies, 1(1), 1-8. doi: 10.32591/coas.ojls.0101.01001u 